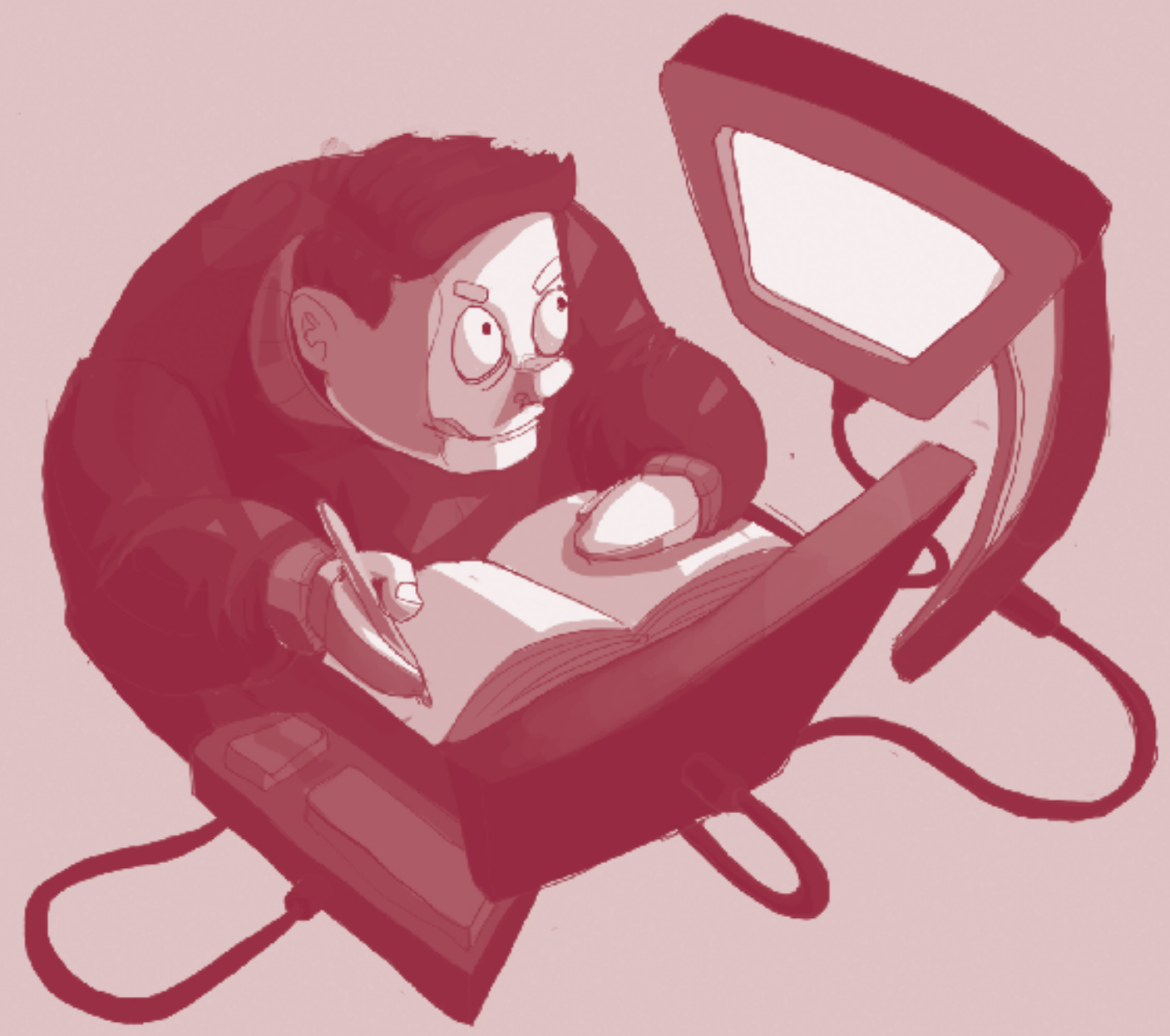

\title{
Educación, nuevas narrativas y corporeidades. Los retos de la escuela desde lo popular y lo digital
}

Education, new narratives and corporeality. The challenges of the school from the popular and the digital

Educação, novas narrativas e corporalidade. Os desafios da escola da popular e digital

Leidy Lorena Chacón Ortíz Andrés Mauricio Páez Ochoa 
Leidy Lorena Chacón Ortíz

Andrés Mauricio Páez Ochoa ${ }^{2}$

Fecha de recepción: 29 de octubre de 2014 / fecha de aprobación: 4 de febrero de 2015

\section{Resumen}

Ante las dificultades monumentales por las que trasiega el aparato escolar y en general la educación, se hace necesario mirar fenómenos que deben ser interpretados desde esta institución social y en los cuales ha de participar la comunidad como posibilidad de permitir que la juventud; sus deseos, sus expectativas y sus propios cuerpos, sean el territorio del encuentro con la paz política en Colombia, con el uso crítico y emancipador de las herramientas digitales y el motor de la movilización social que ellos tienen que promover.

Palabras clave: Juventud, era digital, escuela, cultura popular, conocimiento letrado, nuevos lenguajes.

\section{Summary}

Given the monumental difficulties that racked the school system and education in general, it is necessary to look at phenomenoes can be interpreted from this social institution in which the community has to participate as possible allow the young; their wishes, their expectations and their own bodies, are the territory of the meeting with the political peace in Colombia, with the critical and emancipatory use of digital tools and social mobilization engine they have to promote.

\section{Keywords: Youth, digital era,} school, popular culture, literate knowledge, new languages.

\section{Resumo}

Dadas as dificuldades monumentais que flagelavam o sistema escolar e da educação em geral, é necessário olhar para os fenómenos que podem ser interpretados a partir desta instituição social nos quias a comunidade tem que participar como a capacidade para permitir que a juventude; seus desejos, suas expectativas e seus próprios corpos, são o território do

encontro com a paz política na Colômbia, com a utilização crítica e emancipatória de ferramentas digitais e motor de mobilização social que eles devem promover.

Palavras chave: Juventude, idade digital, escola, cultura popular, do conhecimento letrado, novas línguas. 


\section{Introducción}

- 1 presente artículo pretende ser una reflexión sobre la - escuela y sus avatares, entre los cuales podemos anotar los relacionados con la cultura popular y la cultura ilustrada. Aceptando que los nexos y distancias entre dichas dinámicas se agudizan a diario dentro y afuera de las aulas, pues diversas causas han producido gruesas tensiones en torno a elementos como el conocimiento, la convivencia, lo tecnológico, la familia, los medios de comunicación, el estudiante y el maestro; es pertinente afirmar que quienes componen dicha estructura social se caracterizan por ser niños y jóvenes permeados por fenómenos avasalladores como la publicidad, los medios de comunicación y todo lo relacionado con la era digital.

Sin llegar a los acuerdos necesarios para comunicar asertivamente a la institución escolar con sus realidades inmediatas, la viabilidad de dicha institución se pone en duda y con ello en peligro el hecho de la misma como una de las posibilidades de transformación social que tanto requieren los países pobres, entre ellos Colombia, además de reafirmar la victoria absoluta de la economía de mercado y su modelo de vida, socavándose con ello el ideal del pensamiento crítico como alternativa a la globalización y la deshumanización.

En ese sentido, iniciando la comprensión de lo popular desde el mundo letrado, asimismo la necesidad de escuchar lo académico e institucional desde la orilla del conocimiento común, podría darse el diálogo necesario para la metamorfosis de la escuela y en consecuencia, de la educación a favor del aglutinamiento y la visibilización de otras propuestas que la enriquezcan, además de posibilitar en términos reales, desde dicha tribuna, la extensión y la ampliación de la democracia participativa.

\section{La perplejidad del fenómeno escolar hoy}

A lo largo de los años, la escuela ha sufrido fuertes transformaciones. De ser concebida como una institución encargada de normalizar conductas de adaptación social ha mutado a lo que

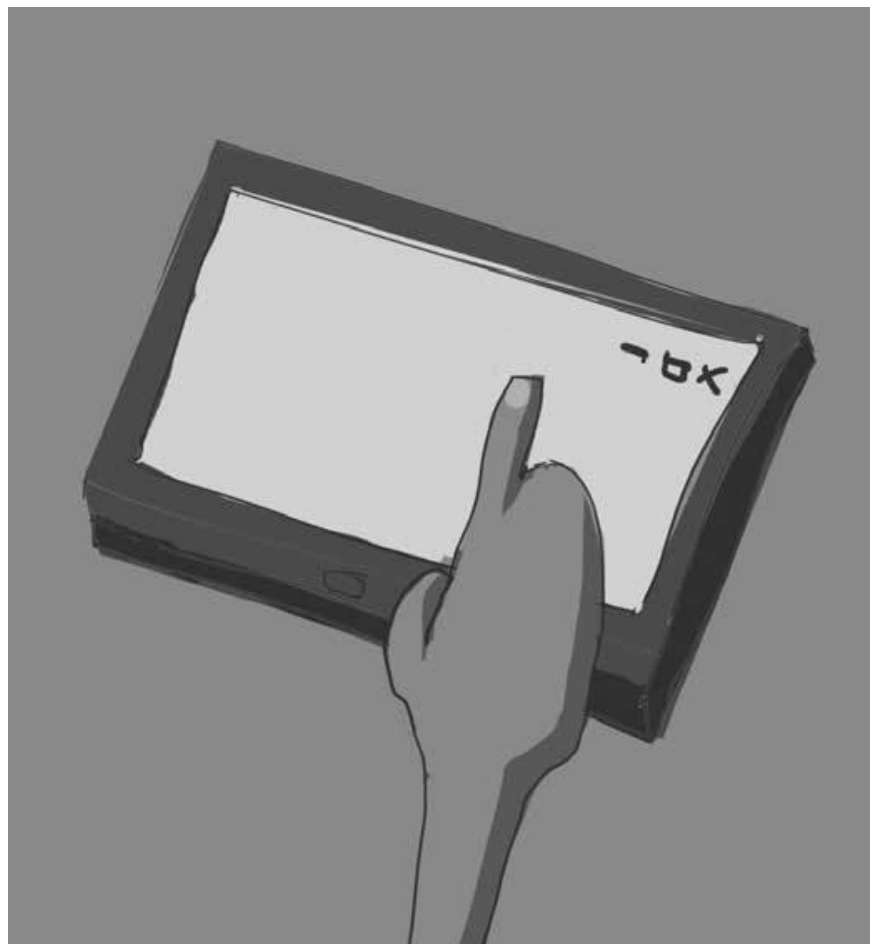

existe, el desparpajo y la irreverencia juvenil a límites que hoy se concretan en el consumo masivo de sustancias psicoactivas, el pandillismo, la deserción o el embarazo adolescente, como ejemplos. Al parecer, la escuela como institución social no puede ni quiere dar respuestas a fenómenos tan graves.

Silvia Bacher (2009) plantea en su obra la visión de estudiantes y docentes quienes se han convencido presuntamente de la inutilidad de la escuela, pues existe una dura confrontación entre cultura juvenil y cultura letrada, y en ese sentido los principios actuales (éticos, sociales, económicos) a seguir se hacen más líquidos e irrelevantes, como diría Bauman (2005). En consecuencia, la escuela tradicional parece romperse en mil pedazos, sus rutinas, su didáctica, la manera de acercarse a la realidad temporal y es ahí donde se afirma que los faros juveniles (Merino Fernández, J. V) ${ }^{3}$ se han disuelto y las preguntas que los contienen, también.

3 Merino Fernández, J. V. Violencia escolar como fenómeno Social y Educativo. Es pertinente enfrentar dicho fenómeno a riesgo de que sea insostenible y se convierta en un problema de salud pública. 
En ese orden de ideas, al mismo tiempo que la escuela se halla en el dilema fundamental entre lo tecnológico y lo enciclopédico, y al parecer ese mundo letrado ha terminado subordinado a lo digital, es imperativo que dicha institución social se reedifique y evite ser la contradictora de la tecnología, debe mediar y pasar a ser el punto inicial de resistencia a la economía de mercado, como lo intuyera Giroux (2003). Es justo observar con precisión dicha intención, en principio lo tecnológico se instituye como estrategia para el consumo mercantil.

Frente al mundo escolar, las pantallas poderosas del mundo se presentan superponiéndose sobre autoridades, padres y docentes, mientras los niños acceden a las tecnologías de forma más segura que los propios adultos. Así, ante la perplejidad de los mayores, los primeros permanecen estar más tiempo expuestos a éstas que en la escuela misma, y del mismo modo que las pantallas deforman, a veces más que educar, la institución escolar se debate en sus propias contradicciones. En esas disyuntivas dentro de la escuela, las pantallas se utilizan más como una excusa que como una herramienta pedagógica, exhibir el aparato subordinando su función pedagógica se hace el objetivo. Como ejemplo, a la vez que avanza la tecnología crecen los niveles de deserción en ciertos grados de la educación básica.

De otro lado, no en todos los sectores sociales existe el acceso a la tecnología, de ahí la necesidad de instituir el derecho a la información como derecho humano y que sea vital una educación de la información, no sólo en términos técnicos, sino respecto a sus potencialidades políticas. Al tiempo que debe existir el acceso a la información que los aparatos proveen, es necesario y ético que exista la multiplicidad de distintos puntos de vista. Como muestra de lo anterior, los medios de comunicación, al ser instrumento del capital y no un poder de control político, reproducen información sesgada, en particular sobre lo que ocurre en la escuela, pues al parecer, maestros y estudiantes son responsables directos de la debacle general que sufre la institución escolar en términos de referencia moral y académica. Teniendo en cuenta que los medios manipulan aspectos de la realidad como el referido, se hace urgente que el Estado defina límites en los contenidos audiovisuales sobre los estereotipos que éstos promueven a diario.

De esa forma, desde el plano de la producción de cultura, la televisión no ofrece variedad local, ni nacional, siendo los niños víctimas del bombardeo mediático en aras de la homogenización y el exacerbado consumo, cuando deberían ser ellos los protagonistas de sus propios programas, imponiéndose el mercado sobre los derechos de la población infantil. Es la puesta en marcha del más radical funcionalismo comunicativo planteado por Merton (1946).

Al tiempo que la televisión ${ }^{4}$ y los medios cumplen con juicio solamente su función de entretener, los discursos políticos orientadores pierden vigencia en la región. De ahí que los jóvenes no se sientan influidos en dicho contexto y en ese escenario, como lo afirma la autora, a ellos no se les pueda exigir lo que no se les ha brindado en términos de formación ético-política. Por ello, es urgente que se geste el giro de la democracia liberal a la democracia social, pues la segunda prepondera la participación política de la gente, no en vano los últimos años han demostrado que las tecnologías digitales se han convertido en un escenario posible de resistencia política y en ese entorno ha de darse la verdadera educación para evitar la disuasión social.

4 Fuenzalida-Fernández, Valerio. Resignificar la educación televisiva: desde la escuela a la vida cotidiana. Es imperativo que los ciudadanos demanden mejores contenidos en la tv teniendo en cuenta el número de horas que los niños consumen en dicho medio.

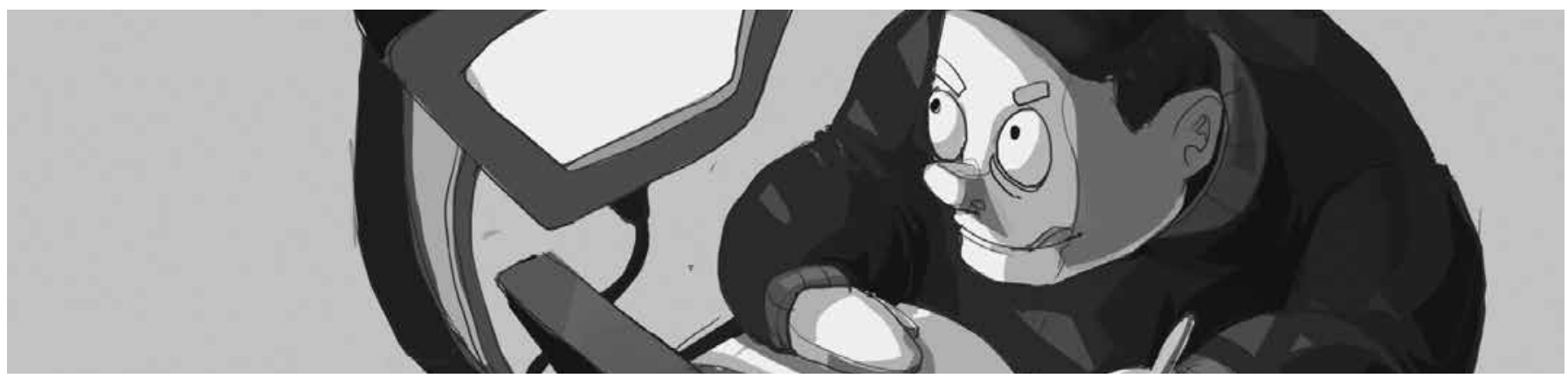


Si en los medios se refleja la decadencia moral de los jóvenes ha de ser en parte porque la escuela y el mundo del adulto no han hecho nada para promover sus derechos y porque esperan reestablecer el concepto tradicional de autoridad.

Sin embargo, las políticas en relación con el uso de las TIC no han logrado elevar el nivel académico de las escuelas latinoamericanas, lo que ha generado mayor atraso y desigualdad, ante ello pedagogía y tecnología deben ir de la mano para promover sociedades equitativas, tanto en términos de poder político como de conocimiento y ciencia. No se trata únicamente de dotar de elementos tecnológicos a las escuelas y vaciarlas al mismo tiempo de contenidos reflexivos, es necesario plantear la discusión frente al uso de la tecnología como herramienta pedagógica y de movilización social.

Por eso es pertinente afirmar que los derechos como discurso no llegan a mejorar la vida de niños y jóvenes, porque ellos no tienen acceso real a éstos; por lo contrario, el Estado ofrece a cambio represión o control punitivo. Las políticas sociales erosionan, mientras la criminalización juvenil aumenta. No advierte el imaginario adulto -Estado, docentes, padres de familia- las profundas transformaciones dadas en la población juvenil y más bien se acomoda en el nostálgico pero anquilosado mundo de la autoridad escolar, mientras los derechos que el adulto le niega al niño son obtenidos en los medios que al final producen desinformación, aparente libertad, discriminación y violencia.

$\mathrm{Al}$ mismo ritmo, la escuela parece ir en dirección contraria a la realidad juvenil, ya que ésta exige de parte de dicha población ciertos comportamientos que evidencien señales en torno a respuestas repetidas, un mundo vaciado de sentido, rituales de urbanidad, higiene, buenos modales, pero sobre todo adaptación social para el trabajo, la religión y la familia ideal. En contravía, la vida juvenil persiste en la búsqueda de valores distintos a la autoridad, su percepción frente a la vida es diferente, no creen en la política del discurso, sino en la acción, el conocimiento que no se acerque a su cotidianidad está hueco de sentido, el temor por la autoridad se transforma en apatía. En un mundo digitalizado, donde los estudiantes aprenden más desde los aparatos electrónicos y los docentes se hallan desmotivados, la escuela parece volverse una institución inviable.

Entonces los niños son objetivo claro del mercado en la reproducción mediática donde la escuela interviene muy poco, a la par que ellos construyen su sujeto en la gratificación del tener y no en la edificación del ser; la escuela es desplazada por la televisión que reconfigura valores políticos y sociales. Parece que los medios se han encargado de profundizar la crisis de dicha institución mostrándola como un lugar violento, donde los maestros son incapaces de detener la violencia estudiantil o aún peor, la promueven. Si en los medios se refleja la decadencia moral de los jóvenes ha de ser en parte porque la escuela y el mundo del adulto no han hecho nada para promover sus derechos y porque esperan reestablecer el concepto tradicional de autoridad.

De esta manera, ante el avasallador control de los medios masivos, la escuela debería comprometerse a ser más llamativa sin dejar de lado el fin pedagógico para atraer otra vez a los jóvenes. Los aparatos por sí solos no lograrán transformaciones importantes, pues junto al poder social y del Estado se podría dar un resultado realmente significativo a la tecnología ante la premisa del mercado de manipular la imagen y en general la información para reproducir el consumo. Las leyes deberían estar al tanto de la regulación de esa información en beneficio de la sociedad y los medios podrían hacer consciencia sobre que los productos informativos que ofrecen están vinculados a la forma en que los niños y los jóvenes ven el mundo. En ese sentido, debe primar su responsabilidad legal vigilada desde el Estado.

Por su parte la escuela, ante el embate del capital sobre el destino de las personas, ha de posibilitar la idea de un mundo alternativo al del consumo que propone el mercado y la 
responsabilidad ético-política debe ser un instrumento capaz de brindar el ingreso humano al mundo de la tecnología. Es muy limitado entender la escuela como aquel sitio donde sólo se forma en conocimientos científicos, como quisieron los ilustrados europeos, o tal vez en aprendizajes estandarizados, en épocas del amanecer industrial. La escuela puede ser un lugar donde en tiempos actuales vamos todos, docentes y niños, a formarnos en conocimientos del mundo en términos de la praxis política, de la resolución de nuestros problemas más urgentes, como el hambre o el cambio climático y además entender al otro en su infinita diferencia enmarcada en la igualdad de derechos, como quisiera Habermas (2005).

Es necesario resignificar la labor docente, su responsabilidad social, su posibilidad de aprendizaje permanente que no se reduce a una condición salarial o a la repetición de contenidos sin contenido, sino el ampliar las luchas permanentes, la comprensión de la existencia, del poder íntimo, pero también colectivo; la desigualdad, pero también la igualdad, la posibilidad de transmitir conocimiento y de dudar de las verdades globalizantes que reproducen los medios como fuente de deseos, muchos de estos frustrados ante la imposibilidad de obtener lo que la televisión vende, son los nuevos retos que esta labor impone. Sin embargo, el sistema mercantil se las arregla para que todos obtengan lo prometido en alguna medida, los niños son un mercado inacabado por lo que parece imposible hacerle frente a la apabullante publicidad, siendo fundamental potenciar las resistencias locales en diversas latitudes, que enmarcadas en objetivos particulares contienen otros referentes de interés para la humanidad.

La escuela no puede anquilosarse en la representación de la idea tradicional de familia que hoy se desvanece también; una idea que promovía la armonía de la autoridad en manos de un patriarcado que vigilaba el que todo se hallara en orden. Ese paradigma está roto y no porque la estructura patriarcal se haya derrotado, sino porque la erosión de los discursos orientadores ha generado que todas las instituciones modernas de orden y progreso estén en crisis profunda. Es la respuesta a una sociedad que exige una nueva mirada en la cual no es posible tratar de sostener por terquedad adulta el deber ser.

Esa crisis ha sido gestada por muchas razones; entre otras, la pretensión del capitalismo global de homogenizarlo todo en un solo sistema de consumo de "bienes", dicha crisis debe ser aprovechada por los componentes del mundo escolar a favor de evitar su desaparición, y al contrario, promover que se transforme precisamente en el hito alternativo a la deshumanizada economía mercantil.

La respuesta de los jóvenes y niños a una escuela que revela exclusión, tradición, aburrimiento y la distancia entre sus contenidos y lo que se ejerce en la realidad es contundente. La era digital propone unos retos que los docentes estamos en la libertad de vencer, el aprendizaje del mundo ya no está en la escuela, se halla afuera, además de ser mediado por aparatos electrónicos diversos. El mundo escolar debería implementar el uso de esa tecnología en un sentido pedagógico, se hace absurdo que hoy se censuren canales de información en la escuela abriendo una brecha mayor entre escuela letrada y mundo juvenil, de ahí que los aparatos han de ser aliados en el trabajo de los docentes. Sin embargo, sin la mediación ética, política y pedagógica de dichos docentes, éstos serán condenados a los museos del ostracismo, porque son los seres humanos los que le dan un sentido a los mismos.

En esa vía, a la par del uso tecnológico en la escuela en contextos urbanos como Bogotá (Pintos, L. 2014) ${ }^{5}$, se debe dar un debate sincero y abierto sobre ciertas cuestiones enlazadas a esta premisa ¿Cuáles son los objetivos del estudiante dentro de los muros escolares?, ¿es el uniforme en la escuela pública un elemento de formación?, ¿existe respeto por diferencias raciales, culturales y sexuales dentro del aula escolar?, ¿es el aparato tecnológico un recurso de reconocimiento del otro?

Dichas respuestas deben ir articuladas a la escuela como aparato de resistencia localizada al sistema de mercado, y así motivar el quehacer diario, en términos de convertir a los estudiantes de la institución escolar en sujetos fundamentales para la transformación de la escuela y de sus propias vidas.

Los jóvenes se hallan expuestos a distintos peligros como el consumo de drogas, las pandillas y la soledad. El volcar a la escuela para darles el protagonismo requerido y que sean sujetos de derechos enriquece su experiencia como seres sociales, para que aporten a las soluciones del mundo, así, los estudiantes derrumban los muros simbólicos de la escuela-prisión, Foucault (2002) evitando que transcurra de forma cicatera el tiempo sobre sus vidas, el vínculo con la vida real condenados a ser

5 Pintos, Laura. Uniformes escolares en la escuela pública, una tendencia en aumento envuelta en polémica. Uno de los debates fundamentales en Bogotá debe ser el de la convivencia y como elemento clave, el uso del uniforme. 
parte de los millones de brazos desempleados o de encontrar algo de afecto e identidad en el "parche" de turno. El objetivo del estudiante en la escuela podría ser adquirir poder político y social para cambiar todo lo que en la actualidad está torcido.

\section{El estigma de ser joven}

Dentro del análisis de la escuela y los sujetos que la componen, presumiblemente nosotros como adultos hemos criminalizado a la población juvenil, pues la segregación ha recaído sobre ellos al mismo tiempo que consumen información sin adquirir poder simbólico, ni real. Ante tal escenario la escuela se ha quedado estática sin ser el vínculo con la movilización inherente a ellos. El Estado desconfía de los jóvenes y ellos del Estado, mientras en los medios los estereotipos recrean modelos de maldad, bondad, fealdad, belleza, etc.

En la calle, policía, adultos y Estado se unen para crear el discurso de la seguridad en detrimento de los jóvenes con el afán de encasillarlos, perseguirlos, pero sobre todo, controlarlos, los medios responden con invisibilización y en la coalición perversa del mundo adulto contra el joven, aquél no exige sus derechos porque asume la relación de su vida impunemente a la violencia y la delincuencia, cerrándose así a espacios sociales, culturales y laborales. Al mismo tiempo, se vuelve política pública sostenerlos en la ignorancia, en la pobreza y en la desconexión social, y la escuela aparece como única tabla de salvación y de restablecimiento de los derechos perdidos.
Si los jóvenes se tranzan en la constante exclusión, para el docente no es distinto, pues la figura de antaño como autoridad intelectual y moral ha desparecido, el carácter del maestro se dibuja en su falta de poder social, combates sin cuartel por una vida digna y la ausencia de reconocimiento de sus estudiantes. Pese a eso, la función humanista del pedagogo persiste, pues su labor de estimular el pensamiento crítico va más allá de la educación bancaria que mencionara Freire (1985) ante el intento de las máquinas por reemplazarlo, es su esfuerzo humanizar esa máquina que se impone y el interpelar el conocimiento científico que se desvirtúa cada vez más.

De ahí que el acceso a la ciencia, como lo entendíamos en un baúl dispuesto para los iniciados, se encuentra abierto para transformarse en una avalancha que avasalla toda la realidad. Así, esa llave que se halla al descubierto en cualquier lado, pone en riesgo la funcionalidad de la escuela y el nuevo docente debe aprender a deshacerse de la tradición sin abandonar lo que aprendió de ella y así formarse en las nuevas sociedades del conocimiento que requieren de su capacidad humana para comprender el mundo y la posibilidad de ser un "cruzador de fronteras" (Bacher, 2009, p. 27).

La figura del docente se desvanece, el mundo del maestro de hoy no es como el de ayer, el actual se somete a la estigmatización y a la falta de reafirmación social y salarial, se le exige a los docentes ser protagonistas en la transformación social, mientras se les desmotiva de innumerables formas, pese a eso, el valor pedagógico de los objetos, la tecnología y la ciencia lo brindan los maestros.

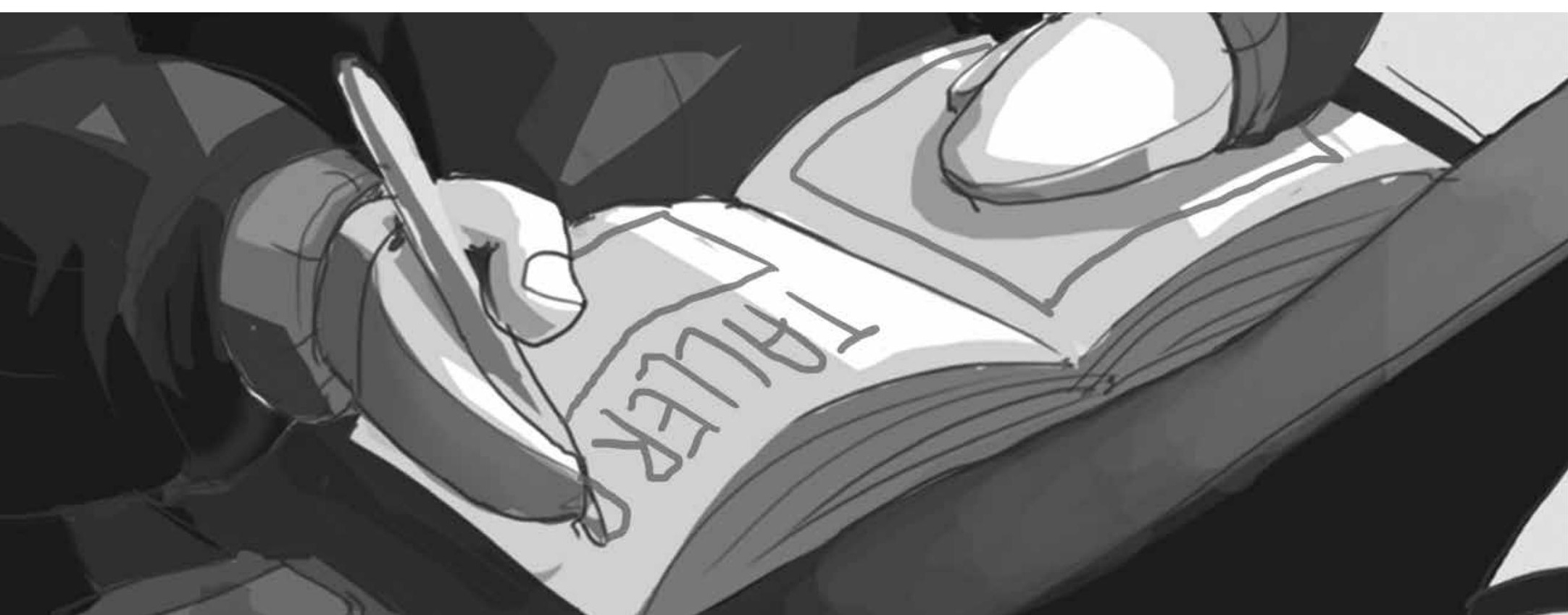




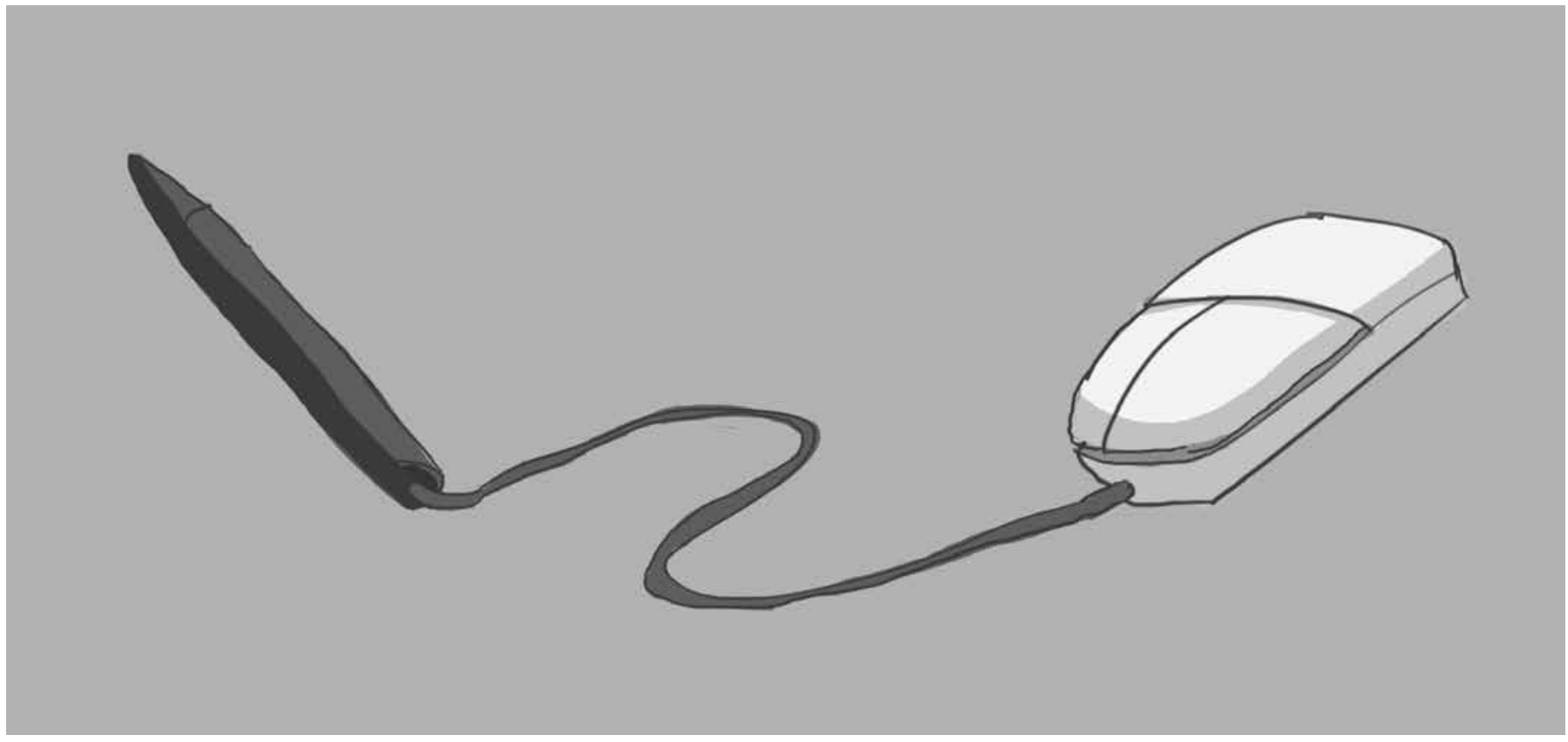

Sin embargo, la educación en América Latina no ayuda como palanca de movilidad social, pues los jóvenes desconfían de todas las instituciones, incluida la escolar. Ante la estigmatización de la juventud, que se ejerce desde todas las tribunas, se hace latente la desesperanza generalizada, lo cual recrea la práctica de la vulneración de los derechos como un proceso normal y legítimo. Como ejemplo, el mercado laboral exige gente cada vez más calificada por menores salarios y a eso hay que agregar que el sindicalismo es un concepto en desuso, e incluso criminalizado.

Frente a tanta desolación surge el lenguaje como posibilidad de expresión que debería nacer en la escuela, pero que se origina en la calle para diseminarse en la urbe. Es ahí donde se promueven los lenguajes populares que los adultos desprecian y que los medios han aprovechado bien para castrar de contenido y cohesión. En esa recuperación del lenguaje como arma de empoderamiento social las escrituras tradicionales se combinan con las nuevas para mediar y encontrarse, para complementarse, pues posibilitan la construcción de subjetividad y de identidad en los jóvenes. Esa ha de ser la función de los aparatos digitales, interpretar esos nuevos lenguajes, devolverle la voz a los excluidos.
Las nuevas formas de comunicar, como camino de expresión juvenil, y con ello los nuevos códigos lingüísticos reconfiguran las identidades a través de los dispositivos digitales, que surge ante lo letrado, tradicional y autoritario del adulto, además del discurso vaciado de contenido que enuncian los políticos, como nueva forma de ser de la cultura popular juvenil que se erige en los medios electrónicos.

En conclusión, es evidente que la estigmatización social de los jóvenes nace de ciertas políticas de Estado latentes, una agenda que desde décadas anteriores se impone en algunos gobiernos latinoamericanos autoritarios, que no avizoran perder o alternar su poder económico-político, pues las élites criollas, que simplemente heredaron el poder monárquico español, no aspiran a ser sucedidas. Así se comprende el fenómeno de las dictaduras militares en otras épocas, las políticas de mercantilización de la escuela y el sometimiento de los jóvenes al consumismo extremo y continuo, ya lo expresaba Giroux (2003).

La juventud siempre representó peligro para todas aquellas sociedades que quisieron sostenerse indeterminadamente en el poder, ya que ésta revela el ánimo ferviente del cambio y la edificación de otras visiones de mundo que el poder establecido en su comodidad no entiende. Es ahí donde el aparato policial del 
Estado, la tradición cultural arraigada y el influjo de otros poderes íntimos como el de la familia y la religión sirven de dique para las intenciones de las masas juveniles ansiosas de nuevas posibilidades.

En ese sentido, funciona la lucha contra las drogas en el mercado externo e interno. A mayores incautaciones, mayor consumo, menor socialización e inversión en salud o deporte por parte del Estado. En la escuela la inversión se hace mínima y qué decir de la educación superior, que en Colombia tiene como punta del iceberg reforzar la Ley 30 para generar en las universidades la profesionalización con exclusivo ánimo de lucro.

No es una lucha solitaria en contra de los jóvenes; medios y gobiernos neoliberales del mundo se han confabulado para desestimular el poder de las nuevas generaciones y que éstas no pongan en riesgo lo ya existente. Sin embargo, como en toda crisis la destreza humana y la de los jóvenes termina imponiéndose para resistir y promover otros mundos factibles.

Entender que las tecnologías digitales sin duda sirven al sometimiento perverso de millones de jóvenes a los guetos de consumo de forma irreflexiva, pero también a la creación de nuevas identidades y códigos lingüísticos se hace interesante y políticamente audaz, pues ante la desolación producida por el abandono y estigmatización del adulto en todos sus matices, los jóvenes se sobreponen y aportan otras perspectivas. En esa senda, lo pedagógico no pierde el sentido y no se queda paralizado en el museo de la escuela tradicional, se une a estas propuestas para empoderar de nuevo a quienes serán nuestro sustento en unas décadas.

Comprender que la era digital no embrutece, sino que permite abrir otras puertas para el lugar social que ha sido negado por la política institucional y por los medios es fundamental para promover escenarios alternativos, es útil situar a los estudiantes en un entorno en el que sin excusas han sido permeados por los medios, lo digital y las modas, al mismo tiempo que la lucha estéril de la institución escolar por prohibir se viene perdiendo a pasos agigantados. El camino por recuperar el respeto verdadero de los estudiantes ha de ser otro.

Hace décadas, previas a la promulgación de la constitución del noventaiuno, era verdadero entender que se formaba al niño en torno a la modelación académica y moral respecto a valores sociales basados en la autoridad. Hoy después de veinticinco años, eso ha variado por lo menos en términos de lo urbano, pues los cambios en todos los renglones de la vida diaria del estudiante dicen que él no asume patrones de autoridad, ni sumisión, ni en casa, ni en la escuela. El espectro es complejo, pero el maestro debe reconfigurar su forma de enseñar el mundo a sus educandos, debe conferir poder a ellos, no sólo porque ellos ya no son apacibles, sino porque necesitan retomar las luchas que han viciado los poderes político, económico y mediático.

\section{El derecho a la comunicación y a la información}

Es imperativo que los docentes trasciendan del aula hacia la realidad, ello además debe ser un acto que refleje el derecho a la comunicación inherente al habla como acto humano, es así que se puede reconocer el hecho de otras culturas alternativas que se hacen presentes con la oralidad, actividad comunicativa que rebasa lo escritural.

Bacher (2009) plantea como posibilidad de esa oralidad el uso comunitario y escolar de la radio como mecanismo de expresión, divulgación política, curricular y pedagógica. El problema es que no existe una estructura sólida para que los docentes implementen estos programas; no obstante, se hace necesario el uso de un medio como este para que obtengan voz los que nunca han tenido. Ante la decidía que ataca el aparato escolar es necesario combatir la falta de uso de las tecnologías, en este caso la radio o la red informática dentro de las aulas, ya que dichas herramientas poseen efectos transformadores dentro del entorno escolar y en el caso particular de la radio, sirve como mecanismo de denuncia, capacitación, inclusión y solución de problemas reales.

Los usos adecuados de la tecnología pueden llegar a tener efectos de cambio sobre las poblaciones más vulnerables, espacios como las redes sociales comunican e incluyen a niños de todas las esferas sociales, sin que en éstas se ponga en cuestión su clase o estrato.

Trascender del aula y la clase son retos de la escuela ejerciendo el derecho a la comunicación, pues ante el desgaste de la misma como institución física y cultural, el maestro tiene como meta hacer que el conocimiento y la formación vayan a otros lugares de la comunidad a través del ejercicio de dicho derecho multiplicándose ésta a través del aparato tecnológico. De todos modos la burocracia y la decidía generalizada son fenómenos que no promueven de forma efectiva el uso de medios tecnológicos como internet, que posee efectos transformadores.

Aunque las dificultades técnicas y humanas obstaculizan la motivación del docente y generan que no se pueda hacer un trabajo exitoso con internet; existen esfuerzos importantes de 
muchos maestros que se enfrentan y hacen vivir experiencias significativas a sus estudiantes. La radio como medio de comunicación incluyente posee efectos revolucionaros, pues los niños pueden vincularse a él como elemento de divulgación y denuncia ante las intenciones del mercado en los medios comerciales y el poco acceso que los niños tienen a discutir o hablar de sus problemas, la radio se propone como alternativa al ejercicio del derecho comunicativo.

La tecnología puede ser una oportunidad de desarrollo para los niños más pobres porque en esos espacios se aglutina, se integra y no se excluye. Espacios tecnológicos como las ciber-redes colaboran a que la población infantil más vulnerable se integre a áreas sociales negadas históricamente, con contenidos de tipo lúdico, educativo y laboral. La telefonía celular es un medio tecnológico que ha democratizado espacios de interacción y socialización, incluso por encima de la red informática, incluso los niños más pobres poseen un celular para comunicarse y dichos aparatos son elementos incorporados a la vida de los estudiantes de forma permanente, de esa forma podrían aprovecharse como instrumentos pedagógicos y comunicativos dentro del aula de clase.

De ahí la insistencia en que los docentes juegan un papel fundamental en torno a los cambios que el mundo requiere, debe convertirse en un emancipador de los estudiantes y considerarse y fortalecerse el papel de los mismos como sujetos capaces de generar transformación en sus estudiantes. Con maestros empoderados se hace más factible el cambio social.

En un ánimo esperancista al mejor estilo de Freire (1985), en el que se involucra el pensamiento divergente como fuente de transformaciones para entender la tecnología como herramienta compleja para el cambio social y la asertividad pedagógica, se hace imperativo llevar a cabo un análisis coherente y real de la escuela, en un mundo donde el crecimiento de las tecnologías digitales está a la orden del día.

Tal como debería ser, este asunto debe partir de la voluntad política del aparato estatal en el que se puedan superar todos los obstáculos burocráticos y así lograr llevar esos recursos a los estudiantes en las diferentes instituciones educativas. De ese modo internet de altas velocidades, radios escolares con todos los avances técnicos, computadores de alta gama y sobre todo maestros empoderados han de ser la clave en la escuela pública desde el interés del Estado para poder saldar esa deuda social y evitar la segregación para ampliar las infinitas posibilidades de aprendizaje y emancipación en los estudiantes.

¿Cómo usar los recursos tecnológicos? Es la premisa que debe tener en cuenta cualquier política de gobierno si su intención es empoderar a los estudiantes de escuela pública, sobre todo a los de población más vulnerable. Ello consistirá entonces en la capacitación adecuada y pronta a la comunidad educativa y cuando se nombra este concepto se hace referencia a estudiantes, directivos, docentes y padres de familia.

¿La educación digital es necesaria únicamente para los estudiantes? La respuesta es no, pues el acceso a las herramientas tecnológicas, mediando en ello lo educativo y lo político, es imperativa en todos lo sectores sociales. El aglutinamiento de todas las personas dentro de la educación es importante porque establece nuevas redes de tejido social que posibilitan otra vez unir a la gente en torno a objetivos colectivos respecto a la solución de problemas comunes.

En ese sentido, hablando de comunidades educativas, por ejemplo en localidades como Ciudad Bolívar6 donde la violencia y la pobreza acechan permanentemente, habría que preguntarse si lo primero por resolver en esos sujetos es el acceso a la tecnología o a los medios informáticos por encima de la satisfacción de problemas como el microtráfico en sus predios o el grave problema de hambre y hacinamiento. Es allí donde el carácter de un Estado solidario y preocupado por la gente debe incidir para equiparar las tecnologías de la información en torno a esas necesidades y a sus posibles soluciones.

Se debe apuntar entonces a la mirada que involucra este tipo de población vulnerada y afectada, pues con capacitación y buen direccionamiento ellos mismos pueden hacer uso de esas herramientas con diversas acciones como la denuncia de actos delictivos, búsqueda de personas perdidas, anuncios clasificados para empleo, reuniones de la comunidad, etc.

Lograr que las emisoras, la red, la telefonía celular y las otras formas tradicionales de comunicación se integren se hace fundamental para llevar a cabo ejercicios de resistencia pacífica ante los fenómenos de exclusión manifiestos y en crecimiento. Éstos representados en la falta de acceso a servicios básicos, delincuencia y desempleo, pues una de las características de la población vulnerable ante estas problemáticas es la conciencia

6 Berzosa, Millán. El Mosco de Ciudad Bolívar. Esta localidad se caracteriza por la violencia y la pobreza, pero también por unas mayorías dignas y llenas de vida, que se sobreponen a las circunstancias. 
colectiva de hallarse aislados y no poder hacer nada, sobre todo en lo referente a los jóvenes, los aparatos comunicativos usados con estos fines llevan esperanza a estas personas.

Es útil entender la relación entre solución de problemas sociales y tecnologías de la información, pues en esa dinámica se halla la respuesta alternativa a unas políticas del mercado que no necesitan ciudadanos empoderados, sino consumidores desaforados. Dentro de esas posibilidades entonces se hace importante saber cuáles son los caminos indicados para establecer una relación seria entre esos dos elementos, una relación que no termine trivializando los problemas de la comunidad educativa o agudizándolos. En torno a ello se afirma que lo pretendido sobre el lugar del docente en la sociedad actual consiste en primer lugar en ser un sujeto empoderado por la comunidad, en seguida reconocido por su importancia política y también por transcender las aulas, es decir convertirse en un activista comprometido.

\section{Conclusión}

Ante las posibilidades de hallarle correlatos objetivos a la cultura letrada representada por la escuela tradicional, la cultura popular particularizada por lo juvenil y el uso de las tecnologías en la expansión de la era digital, es satisfactorio entender que es mucho lo que se puede hacer en términos de la construcción de una educación forjada en los principios del conocimiento de la realidad global, la formación política, la solidaridad colectiva y el acceso a una verdadera democracia participativa.

En consecuencia, son muchos los retos que se producen desde las diversas tribunas: por un lado, el Estado como propulsor de los derechos sociales de la comunidad y su preocupación de nuevo por satisfacer progresivamente las necesidades de la población; un Estado que no permita la cooptación por parte del poder mercantil y privado. Por otro lado, la comunicación urgente de la escuela con el mundo exterior que a fin de cuentas es donde se halla la realidad y el conocimiento, ese mundo exterior es hostil y difícil y en ese sentido, debe ser la institución escolar la llamada a preparar los futuros sujetos de derechos, transformadores de realidades. Por último, el reconocimiento del docente como formador en ciencia, pero sobre todo como arquitecto de patrones éticos y políticos para la conciencia crítica de estudiantes y sujetos en general, un reconocimiento que debe ser estimulado en muchos sentidos ya descritos, así será posible involucrar la era digital no como herramienta del ostracismo humano, sino como posibilidad de divergencia al mercado imponente.

\section{Referencias}

Bacher, Silvia. (2009). Tatuados por los medios: dilemas de la educación en la era digital. Buenos Aires: Paidós.

Bauman, Zygmunt. (2005). Los retos de la educación en la modernidad líquida. Barcelona: Gedisa Editores.

Berzosa, Millán. Cero setenta. Uniandes. http://cerosetenta.uniandes.edu.co/el-mosco-de-ciudad-bolivar/. Recuperado: 29 de octubre de 2014.

Foucault, Michelle. (2002). Vigilar y castigar: nacimiento de la prisión. Buenos Aires: Siglo XXI Editores.

Freire, Paulo. (1985). Pedagogía de la esperanza. Buenos Aires: Siglo XXI editores.

Fuenzalida-Fernández, Valerio. (2011). Revista Comunicar, http://www.revistacomunicar.com/indice/articulo.php?numero=36-2011-03. Recuperado: 29 de octubre de 2014.

Giroux, Henry A. (2003). La inocencia robada: juventud, multinacionales y política cultural. Madrid: Editorial Morata.

Habermas, Jurgen. (2008). Conciencia moral y acción comunicativa. Buenos Aires: Editorial Trotta.

Merino Fernández, J. V. (2010). http://www.editorialconocimiento.cl/reportajes/77-violencia-escolar-como-fenomeno-social-y-educativo.html. Recuperado: 29 de octubre de 2014. Editorial Conocimiento S.A.

Merton, Robert K. (2003). Teoría y estructura sociales. Barcelona: Fondo de Cultura Económica.

Pintos, Laura. (2011). La información.com. http://noticias.lainformacion.com/asuntos-sociales/ninos/uniformes-escolares-en-la-escuela-publica-una-tendencia-en-aumento-envuelta-en-polemica_wJ60nS8PxJfShcKJ8rolI1/. Recuperado: 29 de octubre de 2014. 


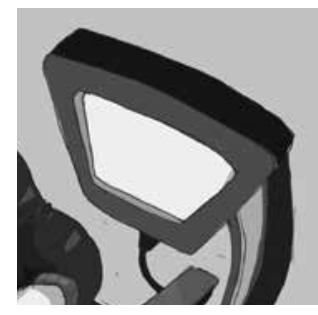

